\title{
Research on Early dismantling head of numerical simulation and experiment
}

\author{
Fu Long ZHAO ${ }^{1, a}$, Xiao Li WANG ${ }^{1}$,Wei WANG ${ }^{2}$ \\ ${ }^{1}$ Guizhou construction science Research \& Design Institute limited company of CSCEC, Guizhou Guiyang, 550006, China \\ ${ }^{2}$ The third construction engineering co. LTD of China construction Forth engineering division CORP. LTD
}

\begin{abstract}
The template support-system projects not only need to complete the range of quality optimization in one construction work, but also to make one of the sound security work. Installation and removal of template support-system are the largest amount of labor. To seek the template works rationalization and reduce the cost of the template works, it is an important way to save a lot of labor and reduce the cost of concrete structure. Therefore, how to improve the template engineering design and its production, installation, operation and removal efficacy effectively and make further reform of the template project for improving the quality of the project are of great significance in the construction of civilization.
\end{abstract}

\section{Introduction}

Early dismantling head of numerical is on the wooden and flute (keel) branch is on a wooden flute template, mean while the concrete pouring, conservation is 10 to 14 days.In order to remove all the templates and the support system, the strength of concrete should be more than $70 \%$. The reasons of not earlier to remove the new pouring is that the early concrete strength is too low.It can not reach the predetermined strength yet under that condtion. However, the concrete structural engineering construction and acceptance are in accordance with the national standards (GB50204-2002) of China provides: Cast-in-place structure of the template and its support removing of the concrete strength should meet the design requirements and it shall meet the following requirements, such as board bottom mold, template span $\leqslant 2.0 \mathrm{~m}$, the concrete strength of $50 \%$ of the design strength before the form removal.

The concrete strength up to $75 \%$ of the design strength before the form removal, when beam arch shell span $\leqslant 8.0 \mathrm{~m}$, the concrete strength of $75 \%$ of the design strength, when the span is greater than $8.0 \mathrm{~m}$, the concrete strength up to $100 \%$ of the design strength before the form removal.

\section{Early removal system}

The key step of early removal template support system to achieve the early dismantling is to make the removal strength of the structure meet the requirements. If the form removal is premature then the concrete structure is easy to break. If the removal of the template is too late, and it is less than earlier demolition there will be other risks. To reinforced the concrete structure is the way to resolve the factors affecting problem. The strength of concrete has a lot of the main ingredients and thickness, including the spacing between the bar diameter and reinforced, etc. This paper use ANSYS to simulate the use of part of the early dismantling architecture and make the analysis of the stress and deflection of concrete and to reinforce ordinary concrete changes over times to gain the diameter of the reinforced ordinary concrete structure by that time. The analysis of the stress and deflection of the structure are in the most unfavorable position, calculated $10 \mathrm{~mm}$ thick reinforced concrete floor when the early removal template support-system minimum form removal strength, and to simulate the cracking of the beam withstand construction loads. Design and make the manufacture of fittings welded to the material with Q235. $\varphi 48$ pipe wall thickness 3.0 or $3.5 \mathrm{~mm}$ steel pipe which is formed on top of the bar in the early removal system. The crossbar class, pole rod through and the connections connected is to form a structure of high dimensional with accuracy, durable, stable performance, There are flexible and convenient loading and unloading steel to support the frame.

\subsection{Model analysis}

\subsubsection{Selection of Model unit type}

Early dismantling head of numerical is to consider as the type of unit to process. Concrete and steel are divided into small units enough as each other, both the stiffness matrix can be solved separately, at the same time taking into account of the reinforcement is a thin material, it can be neglected its transverse shear strength usually, so the

\footnotetext{
a Corresponding author: 308369555@qq.com
} 
fixture can be treated as the line element processing. The bonding element can be inserted between the steel and concrete to simulate the bond between steel and concrete slip. Generally speaking reinforced concrete is in the presence of cracks, while the cracking will lead to steel and concrete deformation of the lack of coordination inevitably, that is to say, it should occur in the losing efficiency slipping of bonding, so the application of such model is the most widely used. ANSYS can consider a separate model: concrete (with Solid65) + reinforced (Link unit or Pipe unit) the paper used unit-with Solid65 unit mainly: Solid65 unit with reinforced or nonreinforced three-dimensional solid model.

\subsubsection{The most unfavourable conditions}

This paper use the induction way to identify the affection of the structural safety performance under the most adverse conditions. If the structural is still safe and effective while the members is in the joint action. So we could summarize favorable and draw in the widespread use of the structure can be the safely using of conclusion relatively. Therefore it is the core to verify the early removal system board structure strength properties which is established by the most unfavorable model.

\subsubsection{Finite Element Modeling}

Concrete slabs. $5000 \mathrm{~mm} \times 5000 \mathrm{~mm} \times 100 \mathrm{~mm}$, with Solid65 unit, modular model, Concrete slab meshing automatic division plate width is divided into 50 equal portions, the plate thickness is divided into 2 equal facilities around the plate reinforced side constraints (Fig. $1 \sim 2)$, early dismantling stigma $.100 \mathrm{~mm} \times 150 \mathrm{~mm} \times$ $50 \mathrm{~mm}$ with SOLID45 unit, in the end of the stigma applied reinforcement side constraints (equivalent to the rigid washer), weight loading $.2 .5 \mathrm{KPa}=2.5 \mathrm{e}-3 \mathrm{MPa}$, the construction loads. 3 days (72 hours) construction load of $1.5 \mathrm{kN} / \mathrm{m}^{2}=1.5 \mathrm{e}-3 \mathrm{Mpa}$, to simulate the top-level conditions, 6 days construction loads for $2 \mathrm{kN} / \mathrm{m}^{2}=2.0 \mathrm{e}-$ $3 \mathrm{MPa}$ to simulation the top-level conditions. The stigma may not have the upper reinforced. Early removal template concrete slab crack width calculation for the design of concrete structures is given during the use phase, which does not apply during the construction period.

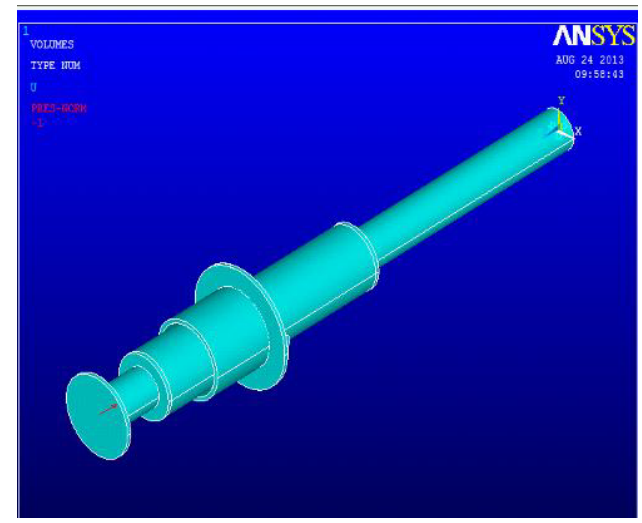

Fig. 1 Model meshing1

\section{Finite element analysis of the bearing capacity}

As previously mentioned, the stable capacity of attached template support frame is controlled by the stable of system. The computing stable theory is main of linear envalue buckling and nonlinear buckling. Thus, this paper is using the finite element method for the attached template support frame system capacity to analysis, and through the finite element software ANSYS to make the stability analysis of the attached template support frame.

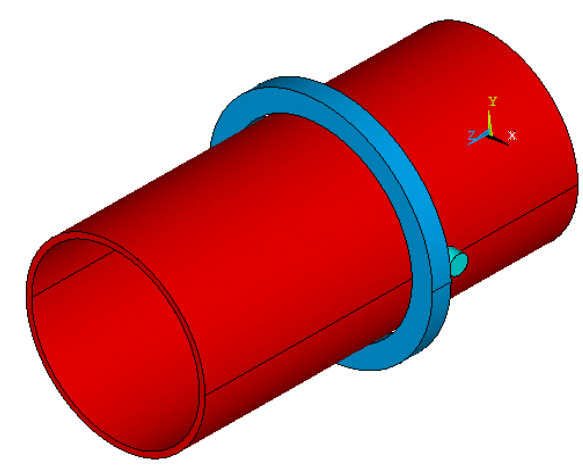

Fig. 2 Model meshing2

\subsection{Captions/numbering}

There are many reasons to cause cracking of concrete structures in the actual project and there are three main reasons: load crack, deformation, cracks and other physical or chemical changes cracks. The deformation cracks is caused by expansion or contraction of the concrete. Concrete is an unevenness brittle material, its tensile strength is low, when the contraction reaches a certain level, the shrinkage stress is greater than the tensile strength of concrete it will crack. The cracks are very different due to many reasons, sometimes in the design we will allocate a portion of the temperature tendons or set the expansion joints of reinforced concrete structures, the aim is to reduce this crack and its adverse effects .Captions should be typed in 9-point Times. They should be centred above the tables and flush left beneath the figures.

\subsection{Positioning}

Physical or chemical changes cracks are caused by the corrosion of carbide. When the carbonation depth of the steel is shown in the surface, the alkaline of concrete would be reduced and loss the protective effect of reinforced steel which rust in the concrete. Then make the concrete (mainly reinforced protective layer) be in tension around, when the tensile strain over concrete ultimate tensile strain value, it will cause the concrete cracked. In design, the measures taken in accordance with the design of concrete structures is under the minimum thickness of the protective layer structural members 
which is not to reach the steel surface and is in the normal period used. The two cracks before can be controlled with the design and construction techniques, for early dismantling template generated cracks load crack. The stigma resulting in structural members makes the stress state changed. But the measure is not suit for the board at the early dismantling era. The stigma may not have the upper reinforced. Early removal template concrete slab crack width calculation for the design of concrete structures is given during the use phase, which does not apply during the construction period. Concrete structure designs for specifications, the use of reinforced concrete structural members by cracks in the tension zone. Basically the homogeneous phase cracks is the concrete tension zone. Because the bond of concrete and steel is cracking, all rally withstand tensile reinforcement. Using finite element analysis can be an effective solution to the design concrete structures. Under the condition that do not consider concrete tension for the basic assumption to analyze the basic situation of the cracks.

\section{3 illustrations}

From the finite element analysis, the lower surface of the concrete slab is almost no cracks, so it can ignore the impact of the load crack in the middle of the construction, when the early dismantling stigma removed, the original early dismantling stigma at the crack part of concrete becomes under pressure then the cracks in the state with the growth of concrete shrinkage, creep, concrete slab it may be closed even healing, so the crack width is guaranteed.The results are shown in Fig. 3 6.

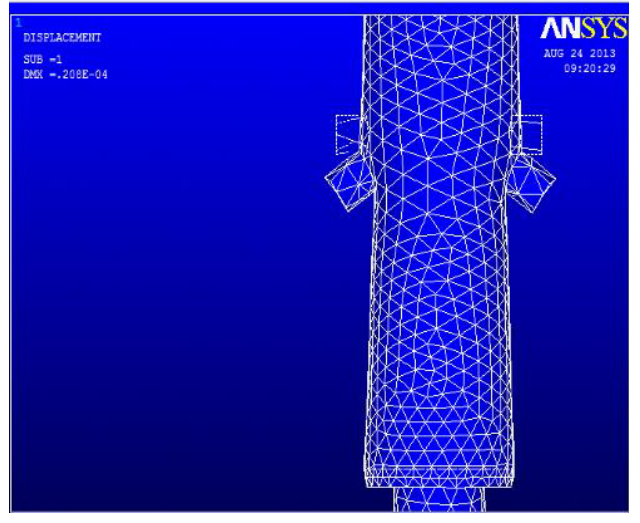

Fig. 3 Stress calculation results 1

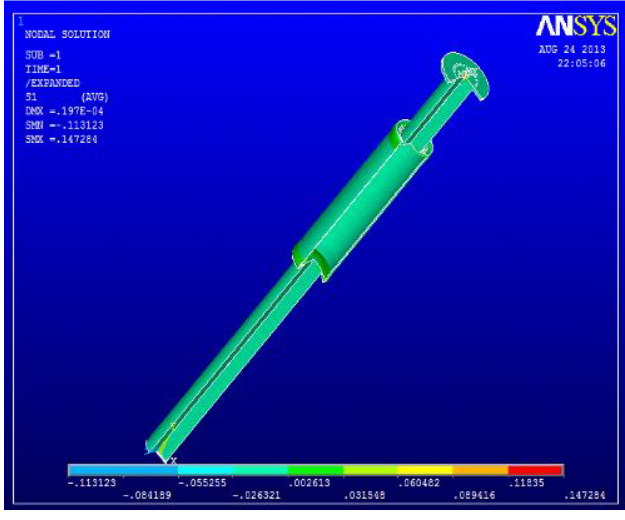

Fig. 4 Stress calculation results 2

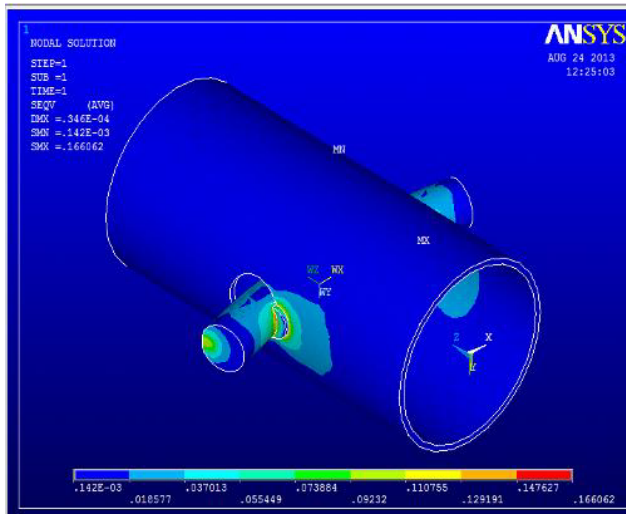

Fig. 5 Stress calculation results 3

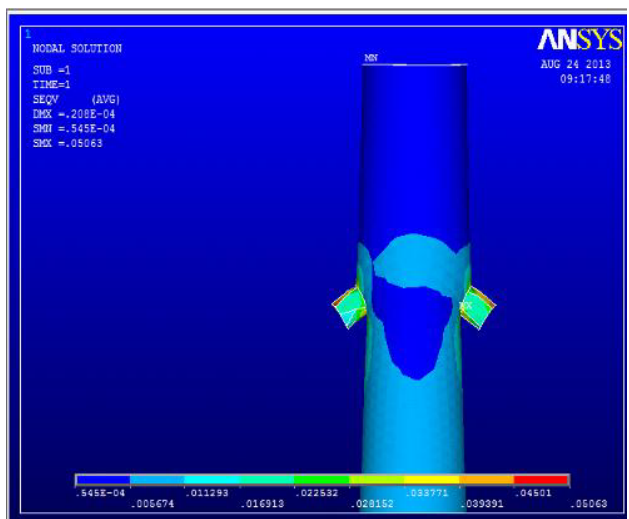

Fig. 6 Stress calculation results 4

In these Figs above, the deflection value is far less than the Design of Concrete Structures (GB 50010-2010) 3.4.3 provisions(China). At that time, the the deflection limits brackets values which apply to use deflection member of the early dismantling formwork construction technology on board deflection control is guaranteed.

At the same time, through the pole, adjustable push rod and the bar ,the composition of early removal template support system could be made.With outlet socket connections, it can form a structure size specification template support. Joint node of the support frame can withstand a certain moment,punching and torque. Plate bracket is to form self stability and spatial structure of the overall stability of the bracket. In the early dismantling system, the pole is as the basic force 
units through the crossbar composition bracket which is adjustable mandrel screw into hole to form a template early dismantling system. As mentioned above, with the early dismantling process principle, in fact, when the long-span is shortened to cross, the required form removal strength will reduce to $50 \%$ of the design strength of concrete, thus it can speed up the turnover rate of the template.

As previously mentioned, the stable capacity of attached template support frame is controlled by the stable of system. The computing stable theory is main of linear envalue buckling and nonlinear buckling.Thus, this paper is using the finite element method for the attached template support frame system capacity to analysis, and through the finite element software ANSYS to make the stability analysis of the attached template support frame.

\section{Summary}

The paper stars with model of early removal template support system and through ANSYS to make the model analysis. Then through the induction to find the worst case model, and in accordance with the model of ANSYS calculations to verify the structural panels tensile stress, compressive stress, cracks, deflection which meet the engineering requirements. So the destruction does not occur, so the attached early removal template support system is reliable.

\section{References}

1. Bangash,M $\mathrm{Y}$ H,Concrete and Concrete Structure:Numerical Modeling and Applications. Elsevier Science Publishers Ltd,1989.

2. Huyse L,Hemmaty Y,Vandewallc L,Finite Element Modeling of Fiber Reinforced Concrete Beams,Proceeding of the ANSYS Conference,Vol.2,Pittsburgh,Pennsylvania,1994.

3. Hemmay Y.Modeling of Shear Force Transferred Between Cracks inReinforced and Fiber Reinforced and Fiber Reinforced Concrete Structures, Proceedings of the ANSYS

4. S-Timoshenko.Theory of plates and shells, 1959.

5. Isenberg J. Finite Element Analysis of Reinforced Concrete Structures II [J],ASCE,1993.

6. Farming P. Nonlinear Models of Reinforced and Posttensioned Concrete Beams. Electronic Journal of Structural Engineering, 2001 (2) :111-119.

7. Erduran E,Yakut A, Drift Based Damage Functions for Reinforced Concrete Columns. Computers and Structures,2004,82 (2-3:121-130.

8. Barzegar,Maddipudi, Srinivas,Three-Dimensional Modeling of Concrete Structures.1:Plain Concrete
Structures.1:Plain Concrete, Journal of Structural Engineering,1997,123 (10:1339-1346. 